\title{
Some properties of milled vanadium phosphates
}

\author{
Władysław Janusz • Svetlana Khalameida • Volodymyr Sydorchuk • Ewa Skwarek • \\ Valery Zazhigalov $\cdot$ Jadwiga Skubiszewska-Zięba $\cdot$ Roman Leboda
}

Received: 29 March 2010 / Accepted: 7 May 2010 / Published online: 30 June 2010

(C) The Author(s) 2010. This article is published with open access at Springerlink.com

\begin{abstract}
Mechanochemical modification of vanadium phosphates doped with $\mathrm{Bi}, \mathrm{Zr}$, Mo has been studied. Milled samples have been investigated by means of XRD, DTA-TG, FTIR, nitrogen adsorption, electrokinetic measurements. It was found that phase composition of the phosphates does not change upon the mechanochemical modification process. Milling in water causes formation of porous materials. Modification of surface results in changes of the electrokinetic and adsorption properties of the milled samples.
\end{abstract}

Keywords Vanadium phosphates $\cdot$ Mechanochemical treatment $\cdot$ Potential $\zeta \cdot \mathrm{Ni}(\mathrm{II}) \cdot$ Adsorption

\section{Introduction}

Acid hydrated vanadium phosphates VPO reveal ion exchange properties in aqueous solutions by means of substitution of proton on cation or reduction intercalation of hydrogen or some cations into interlayer space (Yaroslavtsev 1997; Bruque et al. 1995; Amoros et al. 1989; Philips et al. 1990). Particularly, vanadylhydrophosphate hemyhydrate $\mathrm{VOHPO}_{4} \cdot 0.5 \mathrm{H}_{2} \mathrm{O}$ (VHP) can be related to phosphates $\mathrm{Me}^{\mathrm{IV}}\left(\mathrm{HPO}_{4}\right)_{2}$ which are typical ion exchangers (Yaroslavtsev 1997; Clearfield 1984). Besides, recently, vanadium phosphates apply also as potentially very interesting matrices for Li-batteries (Whittingham 2004; Kishore et al.

W. Janusz · E. Skwarek (凶) · J. Skubiszewska-Zięba $\cdot$ R. Leboda Faculty of Chemistry, Maria Curie Skłodowska University,

M.C. Skłodowskiej Square 3, 20-031 Lublin, Poland

e-mail: ewunias@hermes.umcs.lublin.pl

S. Khalameida $\cdot$ V. Sydorchuk $\cdot$ V. Zazhigalov Institute for Sorption and Problems of Endoecology NAS of Ukraine, Naumova Street 13, 03164 Kiev, Ukraine
2006). In both cases structure of the electrical interfacial layer in aqueous medium and its parameters play conclusive role. Therefore, understanding of processes which take place at the phosphates/electrolyte interface is interesting and important; in particular, the knowledge of the electrokinetic (zeta) potential $\zeta$ of the adsorbent surface allows us to determine the kind and the course of the sorption on the solid. So, there is a correlation between ion exchange capacity and $\zeta$ value, which is closely interrelated to the surface charge, i.e. to the number of surface functional groups (Skwarek and Janusz 2006). By the same token, the surface charge at solid/electrolyte interface is formed due to the acid-base dissociation of $\mathrm{OH}$-groups.

Electrochemical properties can be characterized by the zeta potential, which is the electrical potential of the interface between volume of the aqueous solution and the stationary layer of such fluid attached to the solution cell. It is known that Smoluchowski's formula is generally used to determine the zeta potential of colloidal particles:

$\zeta=\frac{\mu \eta}{\varepsilon_{0} \varepsilon_{r}}$,

where $\mu$ is the electrophoretic mobility (the electrophoretic velocity per unit applied electric field) of particles, $\eta$ is the viscosity of the electrolyte solution, $\varepsilon_{r}$ and $\varepsilon_{0}$ are the relative permittivity of the electrolyte solution and a vacuum, respectively.

At the same time, mechanochemical treatment (MChT) allows to activate solid and, especially, increase its dispersity (specific surface area) and significantly change its surface characteristics (Heinike 1984), including vanadium phosphates (Ji et al. 2002; Ayub et al. 2003). Therefore, the study of interfacial processes solid/liquid for activated phosphates, particularly VHP, in aqueous solutions of electrolytes seems to be interesting and useful. 
The purpose of this work was study of changes of phase composition, design of surface, porous structure and some electrokinetic parameters of precipitated VHP doped with $\mathrm{Bi}, \mathrm{Zr}$ and $\mathrm{Mo}$, and influence of their MChT (milling) in water, air, and ethanol on these properties. Besides, effect of nickel ions presence on zeta potential was determined. Choice of $\mathrm{Ni}$ (II) was not accidental, because it is contaminant in natural environment. Perhaps, it will be possible to use researched adsorbents for $\mathrm{Ni}(\mathrm{II})$ removal from the environment. It should be noted that only the first results are presented in this work.

\section{Experimental}

Pure and doped vanadium phosphates were prepared via precipitation from vanadium pentaoxide and phosphoric acid in presence of organic reducer (Ayub et al. 2003; Hutchings 2004). The typical procedure of synthesis was following: corresponding amounts of $\mathrm{V}_{2} \mathrm{O}_{5}$, oxides of metals (ratio V:P:Me = 1:1.15:0.025 for $\mathrm{Bi}$ or 0.1 for $\mathrm{Zr}$ and Mo), $n$-butanol and oxalic acid were refluxed with excess $\mathrm{H}_{3} \mathrm{PO}_{4}$ for $16 \mathrm{~h}$ at $117^{\circ} \mathrm{C}$. The final solid was separated from the solution by means of filtration and heated up to $270^{\circ} \mathrm{C}$ in vacuum $\left(10^{-4} \mathrm{~Pa}\right)$ for $30 \mathrm{~h}$.

MChT was carried out in a planetary ball mill Pulverisette 6 (Fritsch Gmbh) for 2 h. The reaction mixture consisted of $\mathrm{VPOBi}, \mathrm{VPO}+\mathrm{ZrO}_{2}+\mathrm{MoO}_{3}(\mathrm{~V}: \mathrm{Zr}: \mathrm{Mo}=$ 1:0.1:0.1), $\operatorname{VPOZr}(0.1)+\operatorname{Mo}(0.1), \operatorname{VPOMo}(0.1)+\operatorname{Zr}(0.1)$. The amount of milled reagents was $10 \mathrm{~g}$. XRD measurements were performed with diffractometer PW 1830 produced by Philips using $\mathrm{CuK} \alpha$ radiation. To prevent the forced orientation of the crystallographic planes, samples in the form of uncompressed powders were used for the measurements. Crystallite size $D_{\text {hkl }}$ was calculated from broadening of the most intensive reflexes using Sherrer's equation. Ratio of intensities of lines corresponding to basal and lateral planes of VHP $I_{001} / I_{220}$ was also determined from diffractograms.

Thermogravimetric analysis was made using the Derivatograph-C (MOM, Budapest) in the temperature range 20 $800^{\circ} \mathrm{C}$ with the heating rate $10 \% \mathrm{~min}$. The FTIR spectra in the range $4500-400 \mathrm{~cm}^{-1}$ were registered using the spectrometer "Spectrum-One" produced by Perkin-Elmer (mixtures with $\mathrm{KBr}$ at the mass ratio 1:20). The specific surface area $\mathrm{S}$ was calculated using BET method from adsorptiondesorption isotherms of nitrogen ("NOVA Instruments", Quantochrome Instruments). Effective size of grains $D_{\mathrm{S}}$ was calculated in accordance with formula: $D_{s}=(6 / \rho S)$. $10^{3}[\mathrm{~nm}]$ where $\rho$-density of samples, $\mathrm{g} / \mathrm{cm}^{3}$. Volume of mesopores $V_{\text {me }}$ was also determined from adsorptiondesorption isotherms at relative pressure of adsorbate (nitrogen) close to 1 . Total pore volume $V_{\Sigma}$ which includes volume of meso- and macropores was determined via impregnation of samples dried at $150^{\circ} \mathrm{C}$ with liquid water.

The measuring of zeta potential and particle size distribution was carried out using Zetasizer 3000 (Malvern Instruments) apparatus based on photo correlation spectroscopy (PCS). The potential zeta and isoelectric point $\mathrm{pHiep}$ of the VPO samples has been determined as a function of $\mathrm{pH}$ for $0.1,0.01$ and $0.001 \mathrm{~mol} / \mathrm{dm}^{3}$ solutions of $\mathrm{NaCl}$. The influence of ionic strength, $\mathrm{pH}$, and presence of ions of $\mathrm{Ni}$ (II) at the $\mathrm{VPO} / \mathrm{NaCl}$ solution interface was investigated. $\mathrm{Ni}$ ions adsorption was performed by means of radioisotope method (with ${ }^{63} \mathrm{Ni}$ isotope as a tracer) as a function of $\mathrm{pH}$. The initial concentration of $\mathrm{Ni}$ (II) ions was $10^{-5} \mathrm{~mol} / \mathrm{dm}^{3}$. NaCl solution of concentration $0.01 \mathrm{~mol} / \mathrm{dm}^{3}$ was used as a background electrolyte.

\section{Results and discussion}

According to XRD data, the VHP phase forms during the synthesis of the initial VPO doped with Bi. Next MChT in water and ethanol does not change phase composition of this sample, but leads to an increase ratio of intensities $I_{\mathrm{hkl}}$ of two main patterns: $001(d=0.571 \mathrm{~nm})$ which corresponds to basal plane, inclusive of vanalyl group $\mathrm{V}=\mathrm{O}$, and $220(d=0.294 \mathrm{~nm})$ relating to the lateral plane (Bordes 1987). As can be seen from Fig. 1 and Table 1 (column 8 ), $I_{001} / I_{220}<1$ for initial sample and $>1$ for milled samples. Thus, preferential surface exposure of basal plane with vanadyl groups $\mathrm{V}=\mathrm{O}$ is observed for VPOBi undergone MChT in water and ethanol, which agrees with data of work (Zazhigalov et al. 1997). On the other hand, milling on air results in drastic amorphization of VPOBi sample (Fig. 1).

The curves of DTA-TG for initial and milled samples are presented in Fig. 2. They are typical for the phase of VHP (Cavani et al. 1985; Sidorchuk et al. 2007). The curves contain endoeffect and sharp mass loss at $350-450^{\circ} \mathrm{C}$ and confirm the above mentioned changes of crystal structure. Indicated mass loss for milled samples is lesser than that for initial VPOBi, which is the evidence of partial destruction of VHP phase, degree of which increases in row: ethanolwater-air.

Absorption bands (a. b.) characteristic for VHP (Johnson et al. 1984; Busca et al. 1986) are present on FTIR spectra of initial VPOBi and the sample milled in ethanol (Fig. 3).

Milling in air, which leads to the practically complete amorphization of VHP, results in loss of spectrum resolution in all studied interval. Great shift of all a. b. in the region of higher frequencies (as a rule by $15-35 \mathrm{~cm}^{-1}$ ) and sharp decrease of their intensities are observed for the sample milled in water. Thus, a. b. at $1203 \mathrm{~cm}^{-1}$ (initial VPOBi) corresponding $v_{\mathrm{s}} \mathrm{PO}_{3}$ (Busca et al. 1986) shifts towards 
$1291 \mathrm{~cm}^{-1}$ (milled sample). The latter can be explained by formation of a layer of hydrated amorphous (reprecipitated) VPO on the surface of the sample milled in water.

Crystallite size of VHP calculated on broadening of reflexes corresponding to planes 001 and $220 D_{001}$ and $D_{220}$ according to Sherrer's equation is nanoscale $(18-30 \mathrm{~nm})$. However, crystallites are aggregated in larger grains. Excess of effective grain diameter $D_{\mathrm{s}}$, determined from specific surface area $S$, over crystallite size indicates such aggregation.
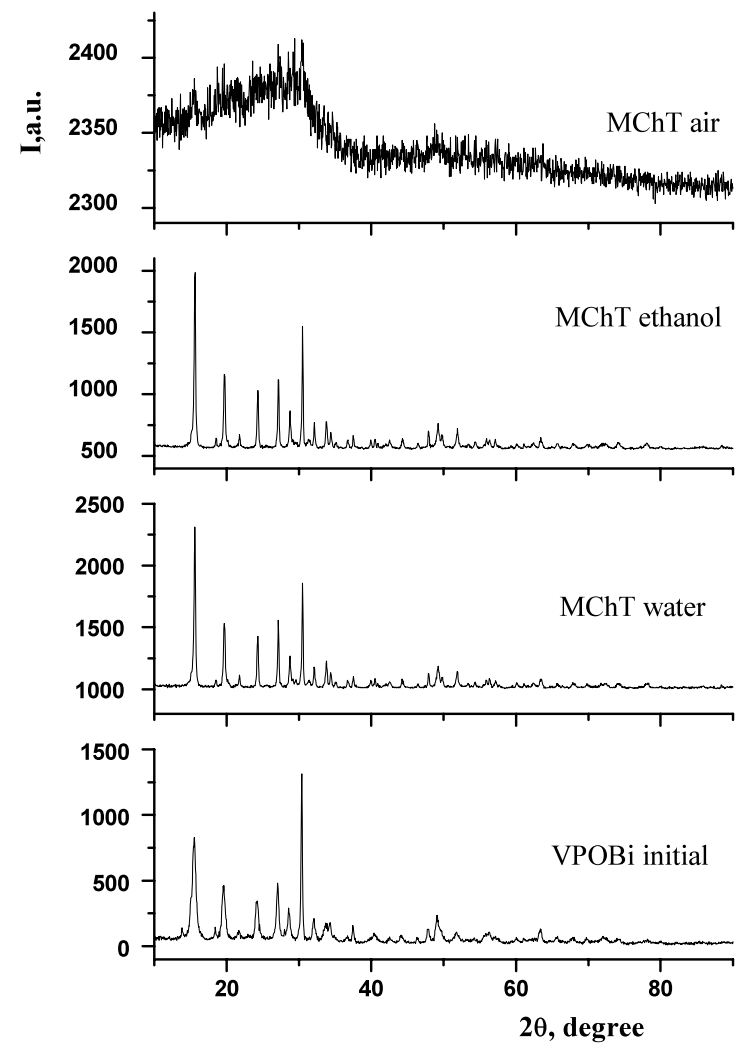

Fig. 1 Powder X-diffraction patterns for VPOBi after treatment in different media
Values of $S$ increase after MChT in all media (Table 1, column 3). Practically nonporous initial VPOBi turns into porous substance due to milling in water: total pore volume $V_{\Sigma}=0.39 \mathrm{~cm}^{3} / \mathrm{g}$, pore volume of mesopores $-0.03 \mathrm{~cm}^{3} / \mathrm{g}$, macrospores $-0.36 \mathrm{~cm}^{3} / \mathrm{g}$.

Similar changes are observed during doping VPO with zirconium and molybdenum oxides via MChT in ethanol. XRD data (Fig. 4) indicate that initial VPO (diffractogram a), VPO doped with Mo or Zr during precipitation (diffractogram does not presented), VPO doped with $\left(\mathrm{MoO}_{3}+\right.$ $\mathrm{ZrO}_{2}$ ) via milling (b), and $\mathrm{VPOZr}$ doped with $\mathrm{MoO}_{3}$ via milling (c) possess structure of VHP with $I_{001} / I_{220}=1.25$. Diffractogram of VPOMo undergone MChT with $\mathrm{ZrO}_{2}$ is superposition of phases of VHP and zirconium pyrophosphate. Diffractogram of this sample (strong background and small intensities of all patterns) evidences that amorphization occurs during milling. FTIR spectra of indicated samples (Fig. 5) confirm above mentioned assumptions.

From Table 1 (samples 5-10) one can see that value of $S$ slightly decreases at dopation of VPO on stage of precipitation and sharply decreases during MChT of VPO with $\left(\mathrm{ZrO}_{2}+\mathrm{MoO}_{3}\right)$ or VPOMo with $\mathrm{Zr}$. On the contrary, specific surface area of VPOZr increases substantially after its milling with $\mathrm{MoO}_{3}$.

In Table 2, value of particles size determined via electroforethic measurements and $\mathrm{pH}_{\text {iep }}$ values for different adsorbents are presented. One can see dependence between particles size (Table 2) and specific surface area $S$ (Table 1): the bigger the particles are, the smaller the $S$ is. In all cases $\mathrm{pH}_{\text {iep }}$ value is around 2, except for initial VPOBi, for which $\mathrm{pH}_{\text {iep }}>3$. This indicates the negative charge of the surface.

Figure 6 shows zeta potential as a function of $\mathrm{pH}$ for the system: VPOBi modified in different media/ $/ 0.001 \mathrm{~mol} / \mathrm{dm}^{3}$ $\mathrm{NaCl} / 0.0001 \mathrm{~mol} / \mathrm{dm}^{3} \mathrm{Ni}$. Zeta potential of all samples in the studied range $\mathrm{pH}$ is negative and decreases with the solution $\mathrm{pH}$ increase. At the same time, $\zeta$ value achieves local minimum at $\mathrm{pH}=5.5$ (and at $\mathrm{pH}=7$ for sample milled in air) and increases in region of higher $\mathrm{pH}$. As can be seen
Table 1 Some properties of VPO samples milled in different media

\begin{tabular}{|c|c|c|c|c|c|c|c|}
\hline$N$ & Samples, conditions of MChT & $\begin{array}{l}S \\
\left(\mathrm{~m}^{2} / \mathrm{g}\right)\end{array}$ & $\begin{array}{l}V_{\Sigma} \\
\left(\mathrm{cm}^{3} / \mathrm{g}\right)\end{array}$ & $\begin{array}{l}D_{\mathrm{s}} \\
(\mathrm{nm})\end{array}$ & $\begin{array}{l}D_{001} \\
(\mathrm{~nm})\end{array}$ & $\begin{array}{l}D_{220} \\
(\mathrm{~nm})\end{array}$ & $I_{001} / I_{220}$ \\
\hline 1 & VPOBi initial & 5 & 0.01 & 310 & 18.3 & 21.3 & 0.64 \\
\hline 2 & $+\mathrm{MCHT}$ ethanol $2 \mathrm{~h}$ & 11 & 0.03 & 140 & 25.0 & 30.6 & 1.27 \\
\hline 3 & $+\mathrm{MCHT}$ water $2 \mathrm{~h}$ & 10 & 0.39 & 155 & 22.9 & 27.8 & 1.25 \\
\hline 4 & $+\mathrm{MCHT}$ air $2 \mathrm{~h}$ & 8 & 0.02 & 195 & - & - & - \\
\hline 5 & VPO initial & 19 & - & 80 & 21.5 & 25.8 & 0.68 \\
\hline 6 & $+\mathrm{MChT}$ ethanol $2 \mathrm{~h}$ with $\mathrm{MoO}_{3}(0.1)+\mathrm{ZrO}_{2}(0.1)$ & 5 & - & 265 & 15.4 & 31.4 & 1.25 \\
\hline 7 & VPOMo(0.1) initial & 14 & - & 105 & 22.3 & 26.0 & 0.72 \\
\hline 8 & + MChT ethanol $2 \mathrm{~h}$ with $\mathrm{ZrO}_{2}(0.1)$ & 7 & 0.37 & 190 & 15.5 & 16.5 & 1.25 \\
\hline 9 & $\operatorname{VPOZr}(0.1)$ initial & 16 & - & 95 & 21.6 & 24.9 & 0.71 \\
\hline 10 & + MChT ethanol $2 \mathrm{~h}$ with $\mathrm{MoO}_{3}(0.1)$ & 38 & 0.53 & 35 & 13.8 & 26.6 & 1.25 \\
\hline
\end{tabular}


Fig. 2 TG-DTA curves for initial and milled VPOBi
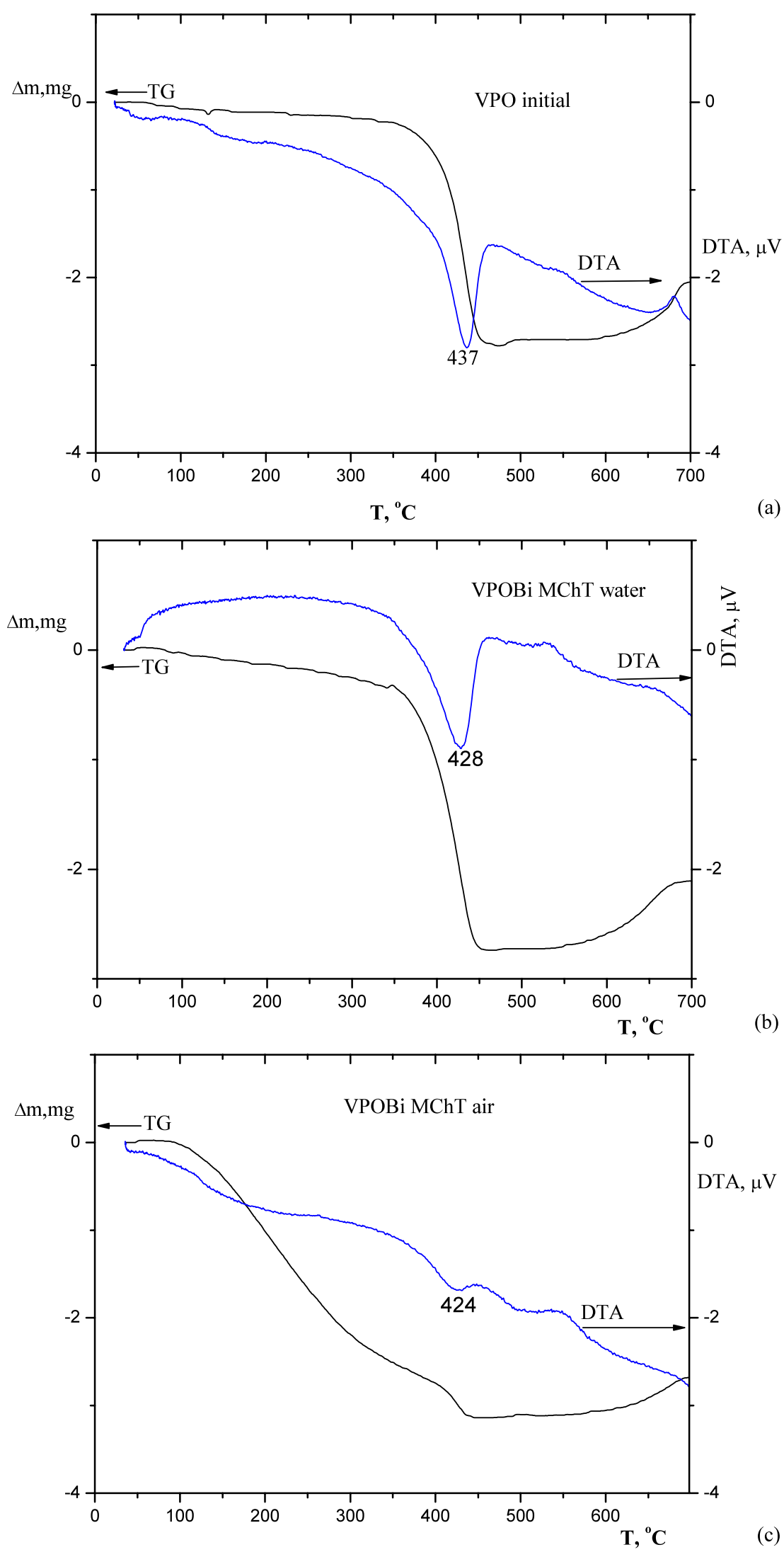
Fig. 3 FTIR spectra of VPOBi after treatment in different media

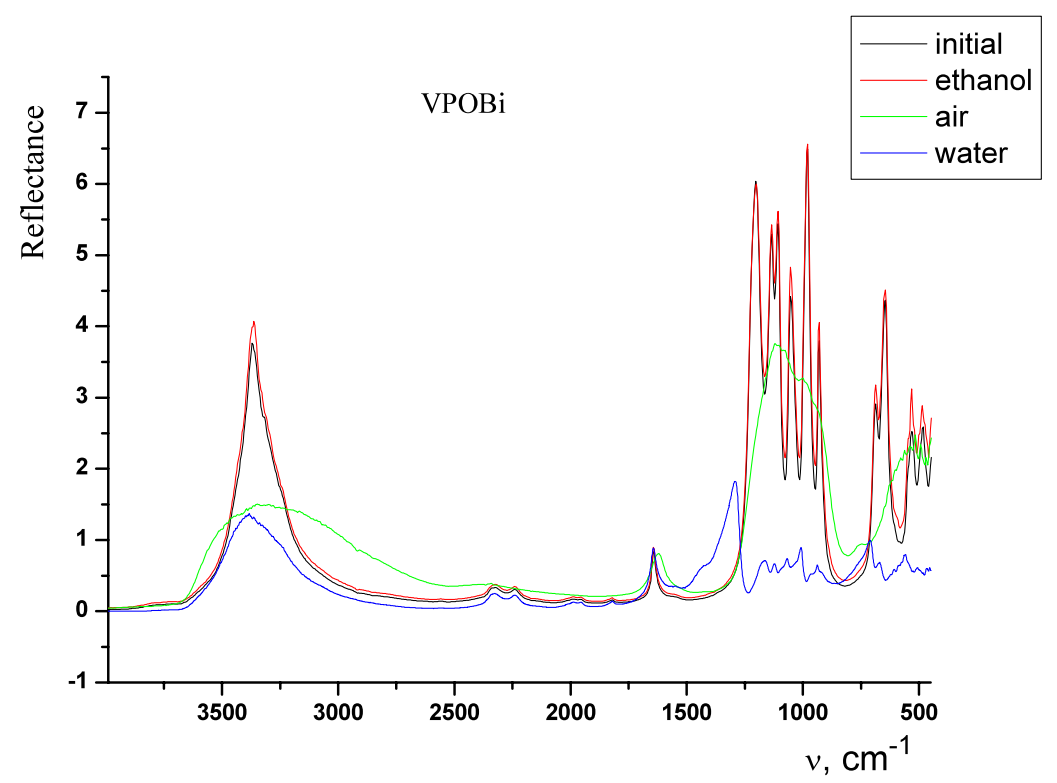

VPOMo (0.1)+MChT Zr (0.1)

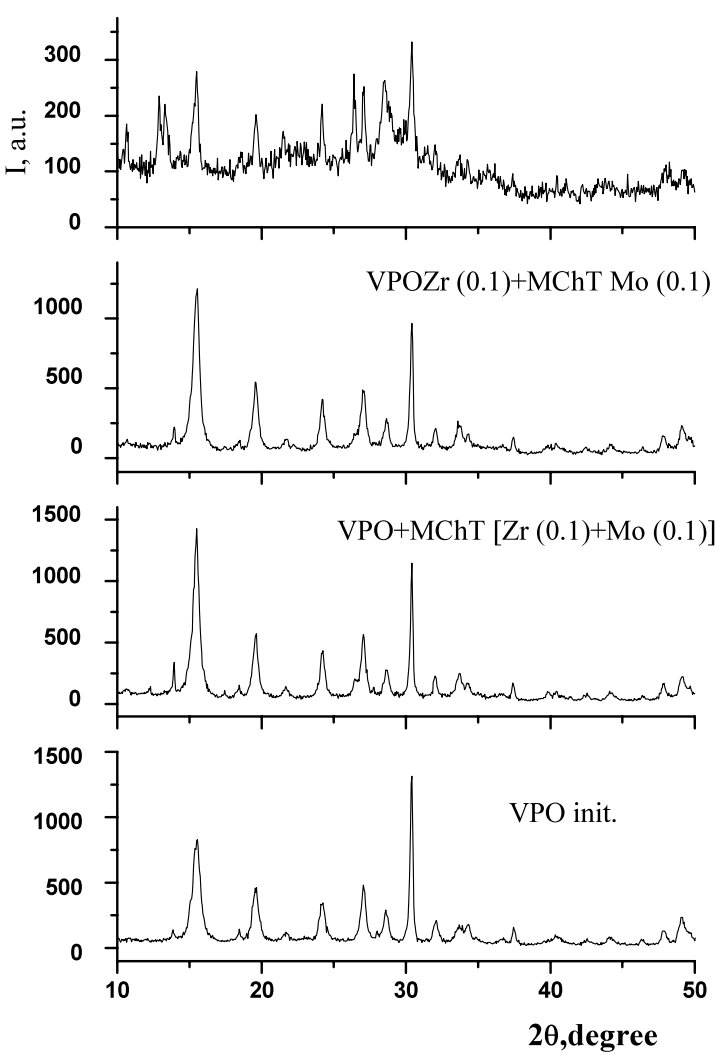

Fig. 4 Powder X-diffraction patterns for samples doped with Mo and $\mathrm{Zr}$

from Fig. 6, overcharging of the diffuse layer, which is associated with $\mathrm{Ni}$ ions adsorption, does not occur in the presence of nickel with concentration $0.0001 \mathrm{~mol} / \mathrm{dm}^{3}$. Therefore, a charge reversal point (CR2) is not observed, as de- scribed for higher content of $\mathrm{Ni}$ and other ions (Skwarek and Janusz 2006; Hunter and James 1992; Kuan et al. 2004). One can see that the samples treated in water and ethanol have close values of specific surface area. Similar changes of zeta potential as a function of $\mathrm{pH}$ are observed for them. Such behavior of these samples may be the result of reactions occurring in the system during milling, i.e. dissociative adsorption of ethanol and water at their surface.

Figure 7 shows the influence of the presence of $\mathrm{Ni}$ on zeta potential depending on $\mathrm{pH}$ for VPO samples doped with Mo and $\mathrm{Zr}$ on precipitation and milling stages. Similar to samples doped with $\mathrm{Bi}$, the increase of zeta potential at $\mathrm{pH}>6$ occurs, but less significant than in case of VPOBi samples.

The example of $\mathrm{Ni}$ (II) ions adsorption as a function of $\mathrm{pH}$ in the $\mathrm{VPOBi} / \mathrm{NaCl}$ solution system is presented in Fig. 8 . This is the sample milled in water. It was found that the adsorption edge of the nickel ions in the studied system increases with increase of $\mathrm{pH}$ values. At $\mathrm{pH}>6.5$, the adsorption remains the same, because almost all nickel ions are bonded by solid phase. Similar isotherm was obtained for VPOBi milled in ethanol. However, sample milled in air does not adsorb $\mathrm{Ni}$ ions when their concentration equals $0.00001 \mathrm{~mol} / \mathrm{dm}^{3}$. The latter can be explained by amorphization of VPOBi during dry mechanochemical treatment. Therefore, only crystal VPO, namely acid hydrophosphate phase, possesses ion exchange properties.

Electrokinetic and adsorption properties of milled vanadium phosphates obviously are determined by their crystal structure and surface design, particularly, appearance of structure defects and greater number of surface hydroxyl groups. However, the relationship of these characteristics is rather complicated. Therefore, additional studies are required for its establishment. 
Fig. 5 FTIR spectra for samples doped with Mo and $\mathrm{Zr}$
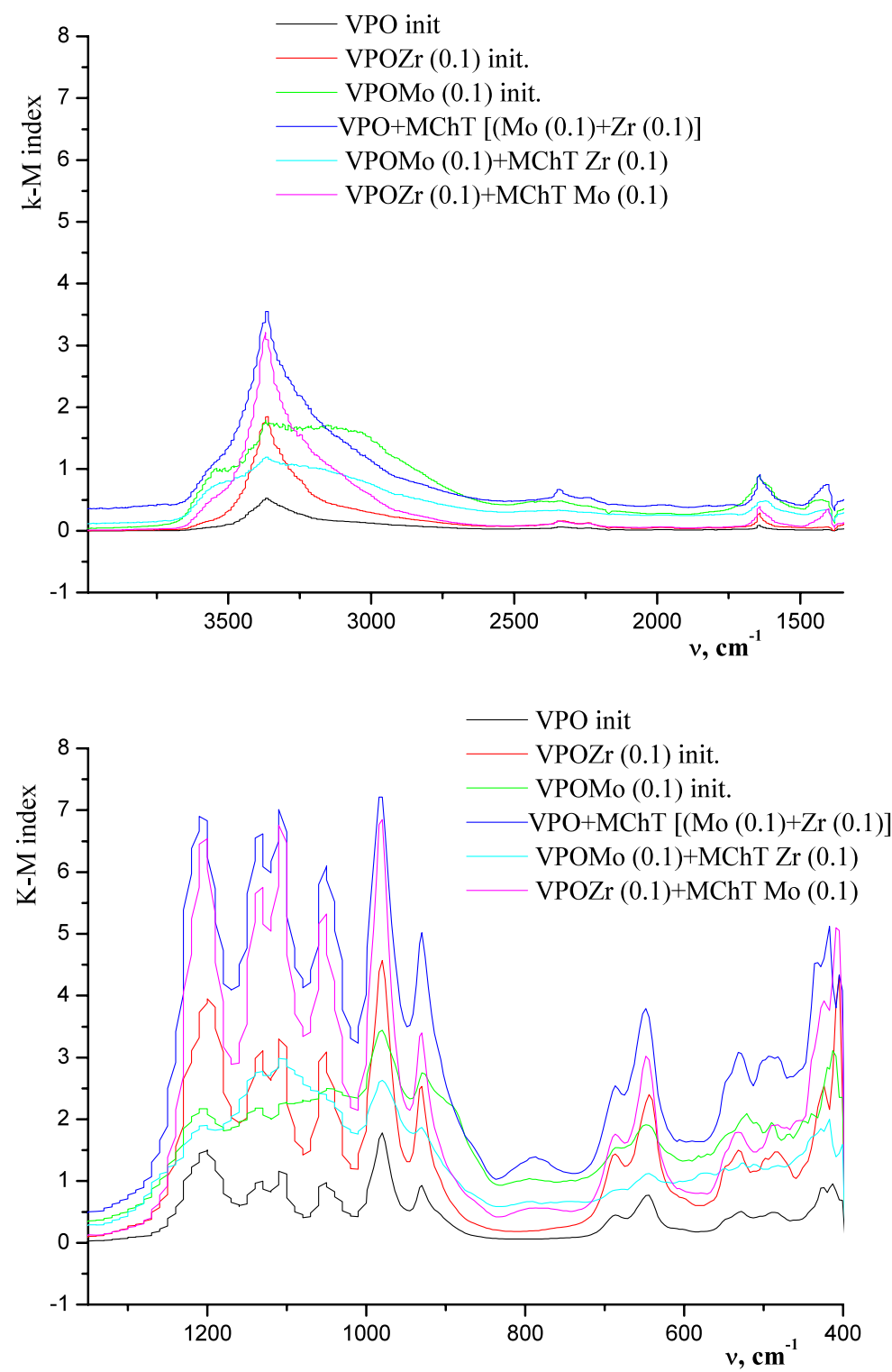

Table 2 Size of particles and $\mathrm{pH}_{\text {iep }}$ for initial and milled samples

\begin{tabular}{clcr}
\hline$N$ & Samples, conditions of MChT & Particles size $(\mathrm{nm})$ & $\mathrm{pH}$ IEP \\
\hline 1 & VPOBi initial & 709 & $<3$ \\
2 & + MCHT ethanol 2 h & 568 & 2 \\
3 & + MCHT water 2 h & 653 & 2 \\
4 & + MCHT air 2 h & 684 & 2 \\
5 & VPO initial & 316 & 2 \\
6 & + MChT ethanol 2 h with $\mathrm{MoO}_{3}(0.1)+\mathrm{ZrO}_{2}(0.1)$ & 712 & $<2$ \\
7 & VPOMo(0.1) initial & 443 & $<2$ \\
8 & + MChT ethanol 2 h with $\mathrm{ZrO}_{2}(0.1)$ & 692 & $<2$ \\
9 & VPOZr(0.1) initial & 332 & $<2$ \\
10 & + MChT ethanol 2 h with $\mathrm{MoO}_{3}(0.1)$ & 235 & $<2$ \\
\hline
\end{tabular}


Fig. $6 \zeta$ potential at

VPOBi $/ \mathrm{NaCl} / 0.0001 \mathrm{~mol} / \mathrm{dm}^{3}$

$\mathrm{Ni}(\mathrm{II})$ solution interface as a

function $\mathrm{pH}$
Fig. $7 \zeta$ potential at samples/ $/ \mathrm{NaCl} / 0.0001 \mathrm{~mol} / \mathrm{dm}^{3}$ $\mathrm{Ni}(\mathrm{II})$ solution interface as a function $\mathrm{pH}$
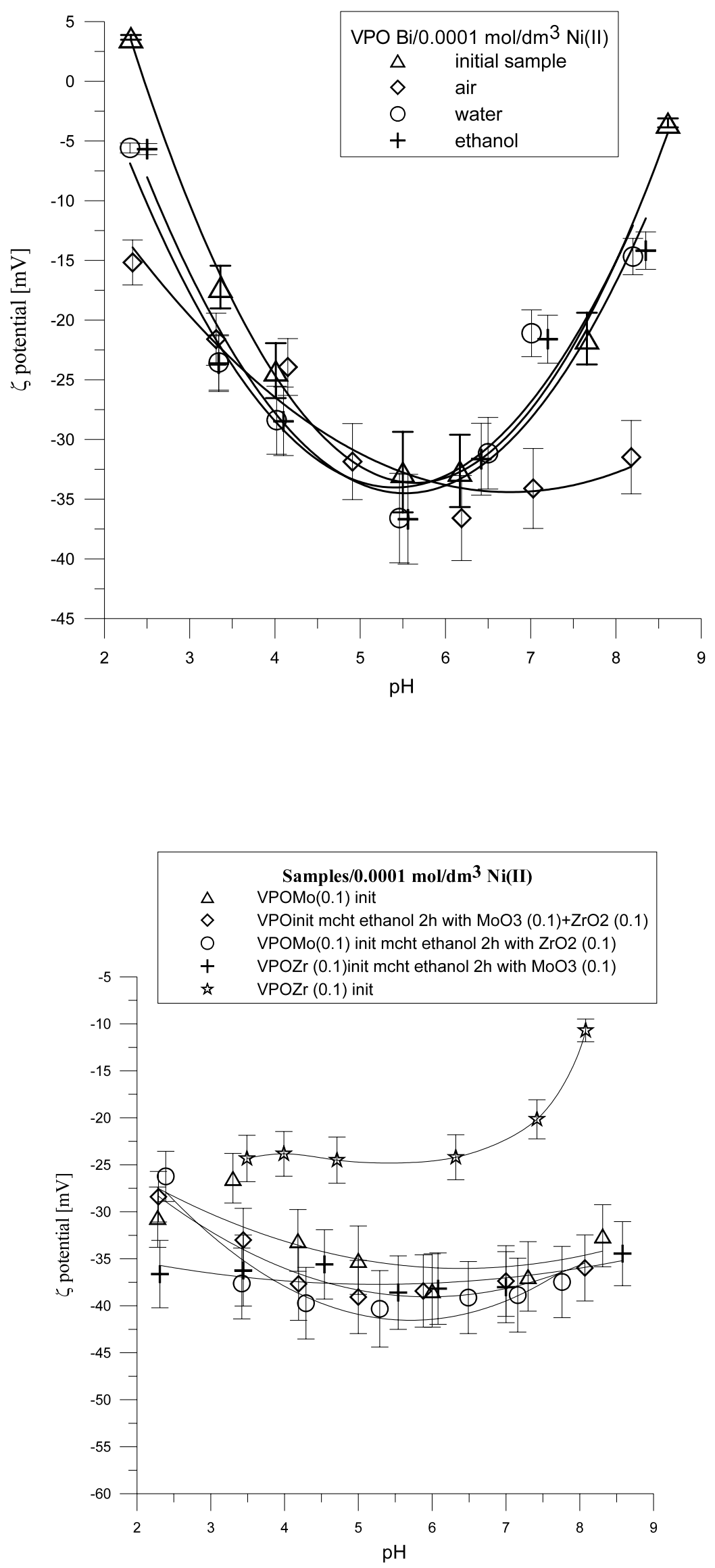
Fig. 8 Adsorption of Ni VPO $\mathrm{Bi} / \mathrm{NaCl} / 0.00001 \mathrm{~mol} / \mathrm{dm}^{3}$

$\mathrm{Ni}(\mathrm{II})$ solution interface as a function $\mathrm{pH}$

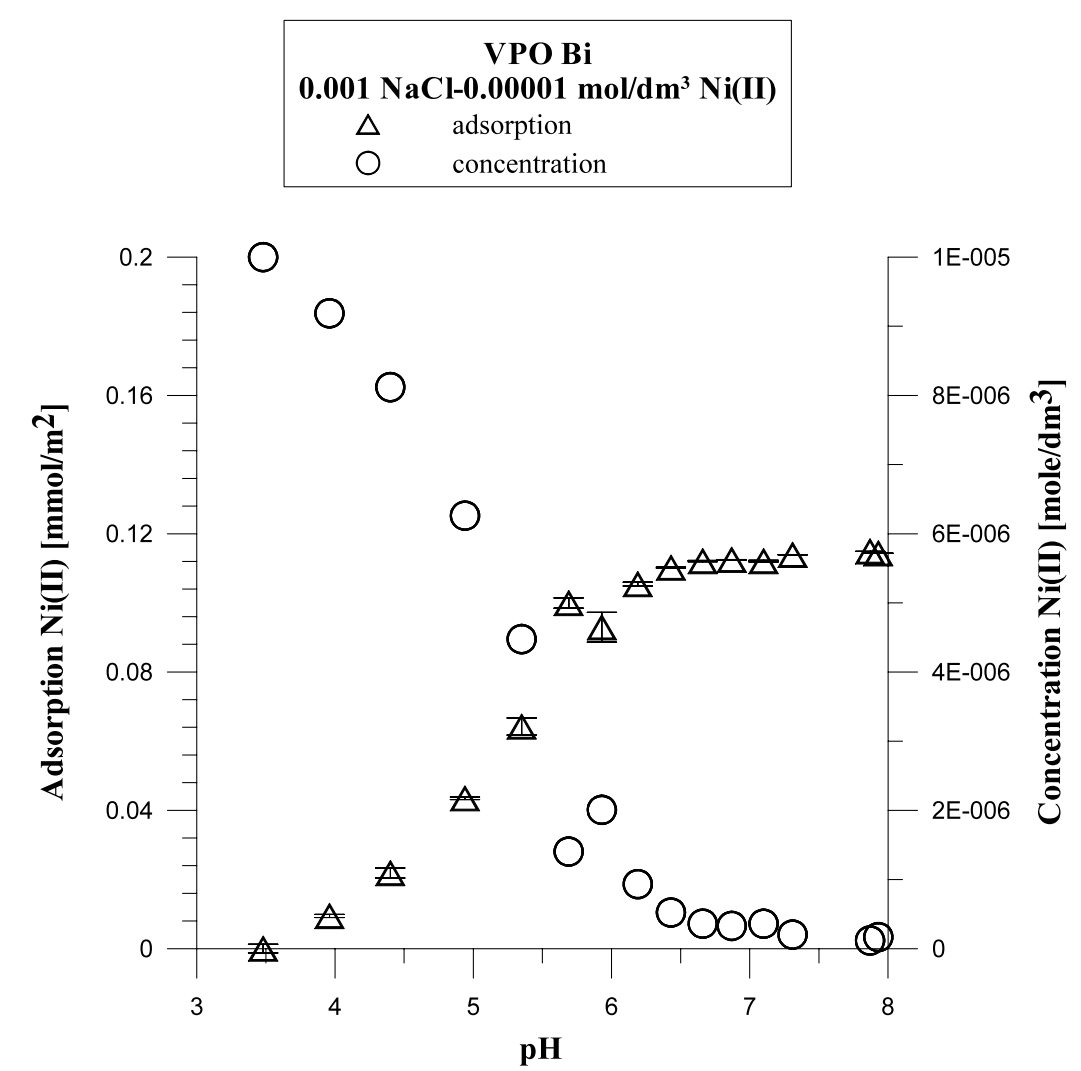

\section{Conclusions}

Mechanochemical treatment of the VPO samples has influence on the surface properties, which was shown by means of XRD, IR, TG-DTA investigations. It was established that their phase composition does not change when milling takes place in water and ethanol, but dry milling results in significant destruction of crystal structure (amorphization). At the same time, noticeable change of preferential orientation of main crystallographic planes occurs: surface content of basal plane sharply increases for all milled samples (except sample prepared via dry milling). The latter and the fact of increase of hydroxyl groups content significantly modify surface design. Presence of $\mathrm{Ni}$ cations with concentration $0.0001 \mathrm{~mol} / \mathrm{dm}^{3}$ does not cause overcharging of the diffuse layer. Destruction of crystal structure of vanadylhydrophosphate during mechanochemical treatment in air results in change of type of dependence "zeta potential-pH" and loss of adsorption capacity. Formation of porous samples during milling in liquid media (water and ethanol) was also established. At the same time, the samples remain nonporous as a result of dry milling in air.

Acknowledgements This work was supported by the European Community under a Maria Curie International Research Staff Exchange Scheme (IRSES), Project No. 230790.

Open Access This article is distributed under the terms of the Creative Commons Attribution Noncommercial License which permits any noncommercial use, distribution, and reproduction in any medium, provided the original author(s) and source are credited.

\section{References}

Amoros, P., Ibanez, R., Martinez, E., Beltran-Porter, A., BeltranPorter, D., Villeneuve, G.: New vanadyl hydrogenphosphate hydrates: electronic spectra of the $\mathrm{VO}^{2+}$ ion in the $\mathrm{VO}\left(\mathrm{H}_{x} \mathrm{PO}_{4}\right)_{x} \cdot y \mathrm{H}_{2} \mathrm{O}$ system. Mater. Res. Bull. 24, 1347-1360 (1989)

Ayub, I., Su, D., Willinger, M., Kharlamov, A., Ushkalov, L., Zazhigalov, V., Kirillova, N., Schlögl, R.: Tribomechanical modification of Bi promoted vanadyl phosphate systems 1: an improved catalyst and insight into structure-function relationship. Phys. Chem. Chem. Phys. 5, 970-977 (2003)

Bordes, E.: Crystallochemistry of V-P-O phases and application to catalysis. Catal. Today 1, 499-526 (1987)

Bruque, S., Lara, M.M., Moreno, L., Ramirezcardenas, T., Chaboy, J., Marziali, M., Stizza, S.: EXAFS structure and electrical properties of lithium niobium phosphate. J. Solid State Chem. 114, 317-325 (1995)

Busca, G., Cavani, F., Centi, G., Trifiro, F.: Nature and mechanism of formation of vanadyl pyrophosphate: active phase in $n$-butane selective oxidation. J. Catal. 99, 400-414 (1986)

Cavani, F., Centi, G., Trifiro, F., Poli, G.: Structure and reactivity of vanadium-phosphorus oxides. J. Therm. Anal. 30, 1241-1251 (1985)

Clearfield, A.: Inorganic ion exchangers with layered structure. Annu. Rev Mater. Sci. 14, 205-229 (1984)

Heinike, G.: Tribochemistry. Akademie-Verlag, Berlin (1984) 
Hunter, R.J., James, M.: Charge reversal of kaolinite by hydrolyzable metal ions: an electroacoustic study. Clays Clay Miner. 40, 644649 (1992)

Hutchings, G.J.: Vanadium phosphate: a new look at the active components of catalysts for the oxidation of butane to maleic anhydride. J. Mater. Chem. 14, 3385-3395 (2004)

Ji, W., Xu, L., Wang, X., Hu, Z., Yan, Q., Chen, Y.: Effect of ball milling on the doped vanadium phosphorus oxide catalysts. Catal. Today 74, 101-106 (2002)

Johnson, J.W., Jacobson, J., Brody, J.F.: Preparation and characterization of vanadyl hydrogen phosphate hemihydrate and its topotactic transformation to vanadyl pyrophosphate. J. Am. Chem. Soc. 106, 8123-8128 (1984)

Kishore, M.S., Pralong, V., Caignaert, V., Varadaraju, U.V., Raveau, B.: Synthesis and electrochemical properties of a new vanadyl phosphate: $\mathrm{Li}_{4} \mathrm{VO}\left(\mathrm{PO}_{4}\right)_{2}$. Electrochem. Commun. 8, 1558-1563 (2006)

Kuan, W.H., Lo, S.L., Wang, M.K.: Modeling and electrokinetic evidences on the processes of the $\mathrm{Al}(\mathrm{III})$ sorption continuum in $\mathrm{SiO}_{2(\mathrm{~s})}$ suspension. J. Colloid Interface Sci. 272, 489-497 (2004)
Philips, M.L.F., Harrison, W.T.A., Gier, T.E., Stuchi, G.D., Kulkarni, G.V., Burdett, J.K.: Electronic effects of substitution chemistry in the potassium titanyl phosphate $\left(\mathrm{KTiOPO}_{4}\right)$ structure field: structure and optical properties of potassium vanadyl phosphate. Inorg. Chem. 29, 2158-2163 (1990)

Sidorchuk, V.V., Diyuk, E.A., Zazhigalov, V.A.: Phase evolution in $\mathrm{V}_{2} \mathrm{O}_{5}-\mathrm{H}_{3} \mathrm{PO}_{4}-$ organic component systems during barothermal treatment. Inorg. Mater. 43, 406-411 (2007)

Skwarek, E., Janusz, W.: Adsorption of $\mathrm{Ni}$ (II) ions at the $\mathrm{Fe}_{2} \mathrm{TiO}_{5}$ /electrolyte solution interface-the electrical double layer structure. Physicochem. Probl. Miner. Process. 40, 149-159 (2006)

Whittingham, M.S.: Lithium batteries and cathode materials. Chem. Rev. 104, 4271-4290 (2004)

Yaroslavtsev, A.B.: Ion exchange in the inorganic sorbents. Russ. Chem. Rev. 66, 579-596 (1997)

Zazhigalov, V., Haber, J., Stoch, J., Kharlamov, A.: Influence of the mechanochemical treatment on the reactivity of V-containing oxide systems. Solid State Ionics 101-103, 1257-1262 (1997) 